\title{
An Investigative Study on Technology Impact on the Quality of Working Life in a University Healthcare and Pharmacy
}

Andrea Daly ${ }^{*}, 1$, Dean Richardson ${ }^{2}$, Sean Thorpe ${ }^{2}$

${ }^{I}$ College of Health Sciences, School of Pharmacy, University of Technology, Jamaica, Kingston, Jamaica

${ }^{2}$ Faulty of Engineering and Computing, University of Technology, Jamaica, Kingston, Jamaica

\begin{tabular}{l} 
A R T I C L E I N F O \\
\hline Article history: \\
Received: 14 April, 2019 \\
Accepted: 06 August, 2019 \\
Online: 23 August, 2019 \\
\hline Keywords: \\
Electronic health records \\
Electronic medical records \\
Health information systems \\
Information systems \\
Change Management \\
Conceptual framework \\
Computerized provider order \\
entry
\end{tabular}

\begin{abstract}
A B S T R A C T
The purpose of this study was to investigate the impact of the implementation of the Online Appointment Scheduling system and Pharm Partner system technologies on the quality of working life for users in a small healthcare environment at the University of Technology, Jamaica. Both qualitative and quantitative methods were employed. Two data collection instruments were: interviews and survey forms. The sample included Health Clinic and Pharmacy staff and users of these facilities. The investigation covered a one (1) year period. The Statistical Package for the Social Sciences software version 24.0 and NVivo software were used for data entry and analysis of the surveys and interviews respectively. Findings supported that the systems improved users' quality of working life. Reduced waiting time for patients to access doctors and receive their prescription from both facilities. Pharmacists were able to dispense drugs to patients at a faster rate. Most manual functions at both facilities were automated: the retrieval of patient's appointment scheduled information at health clinic and the retrieval of patient's records at the pharmacy. Pharmacy inventory system was automated, patients at the health clinic were able to go online and see doctors available for appointments.
\end{abstract}

\section{Introduction}

The University of Technology, Jamaica Health Clinic provides services in the form of general medical care, family planning, emergency care with referral to hospitals and specialists, health and grief counseling and health presentations. Prior to the implementation of the Online (internet/Computer network connectivity) Appointment Scheduling system, most of their processes were manually driven. Patients were seen on a first come basis except for emergencies and overcrowding of the facility was an issue.

This resulted in the implementation of Online Appointment Scheduling system to replace the walk-in or call-in appointment system. It took approximately nine (9) months to complete the full implementation, which was done on July 21, 2014. Due to financial concerns, an in-house software system was developed by the Enterprise. Application System office (ESA) along with the Learning Technology Support Unit (LTSU) instead of the purchasing of an off-shelf software system.

*Corresponding author: Andrea Daly, University of Technology, Jamaica, adaly@utech.edu.jm
The primary factors that drove the implementation of the Online Appointment Scheduling System were the need to reduce waiting time for patients of the health facility. There was a need also to reduce health facility processing time and stream line operations. The secondary factors were to provide real-time appointment listing, improved quality of service delivery, improved process flow, reporting and to automate some processes that were manually driven.

The University of Technology, Jamaica Pharmacy provided services (which are not limited to) dispensing of prescriptions, Over the Counter (OTC) medications, general information, blood pressure monitoring and patient counseling. Prior to the implementation of the Pharm Partner system, most of their processes were manually driven. Operations were manually intensive with the use of Cardex card system. Staff had to manually locate patient's records which were stored in cabinets, stock and dispense drugs by manually checking the shelves for available drugs and conducted manual inventory filings.

The Pharm Partner system was implemented in the University Pharmacy over ten (10) years ago to automate these processes. 
The primary factors that drove the implementation of the Pharm Partner system were the length of time taken to serve patients as most of the processes were manually driven such as the processing of prescription and medical insurances; patients' records were manually stored in file cabinets and their inventory system was manual. A system was required with the following criteria, accuracy, most current version, user friendly and the cost.

Minimal research has been conducted in this area in Jamaica and the Caribbean up to the time that investigated the impact of these technologies on the university population quality of working life. The Aim of this research was to assess user's feedback on what impact to their quality of working life and what improvements were caused by the implementation of the University Online Appointment Scheduling system and the Pharmacy Pharm Partner system. The study also investigated how patients were impacted by the implementation of these technologies.

\section{Related Work}

The research provided the state of the art with respect to the technology adoption and the perceived impact on users' quality of working life and improvement to the customer experience of such systems within the healthcare environment.

\subsection{Conceptual Framework and the Technological Impact on the Changed Management Process}

Works carried out by [1], where the authors that examined the implementation of an Electronic Health Records (EHR) system in a small family medicine residency clinic in the University of Wisconsin. They used three data collection instruments to evaluate user experience, work pattern changes, and organizational changes related to the implementation and use of the EHR system. These were an EHR user's survey, interviews with key personnel involved in the EHR implementation project and a work analysis of clinic staff.

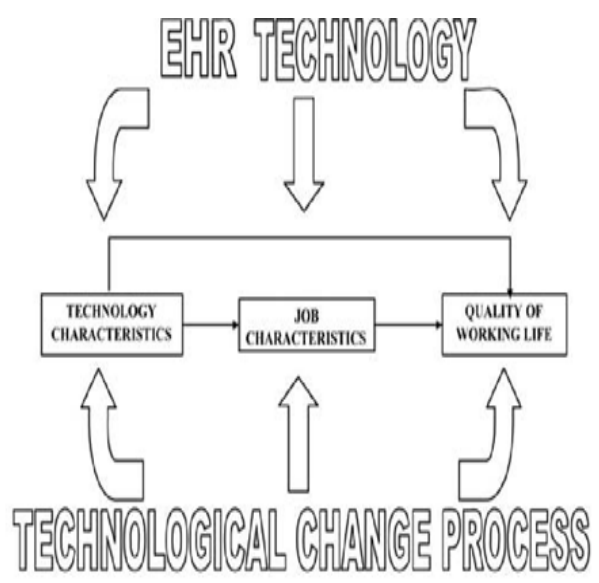

- Technology characteristics: type of technology, functionality, and usability issues

- Job characteristics: job control, workload, uncertainty/clarity, challenge, and role ambiguity

- Quality of working life: job satisfaction, stress, self-reported health, and perceived performance

- Technological change process: employee participation, feedback, project management, information and communication, and training and learning

Figure 1. Impact of EHR technology on quality of working life and performance
Both [2] and [3] examined different frameworks that were appropriate for Health Information Systems implementation and adaptation. However, [2] wanted to know if the technology implemented were actually delivering on the purpose it was implemented for. So [4] explored the present state of technology adoption, where it should be and the gaps that exist and what can be done about it, while [5] examined the benefits and barriers of the technology implementation. However, [6] believed that the technology should be investigated further to see if its implementation and use improved the quality of life. But [7] believed that it was important to investigate if the implementation of the technology impacted more than just the quality of life of users. While [8] believed in doing this the factors and influencers to the technology implementation must be examined. This was further explored by this research along with an examination of [9] change management process to assess changes in the Health Clinic and Pharmacy environment at University of Technology.

\subsection{Factors and Influencers to the Technology Implementation}

Accordingly [8] concluded that health system stakeholders cannot expect their health care system's performance to meet the increasing demand placed on it, unless interventions were taken. The authors believed that health information systems were seen to be one solution to the pending problem and such solutions can assist physicians in tracking patient medical history, interventions, encounters, lab test results as well as managing allergies and drug contraindications. The authors stated that implementations were not simple technical projects. Implementation as believed by the authors comes with risks, the apprehension over which can paralyze a health information systems project in its tracks or even prevent it from starting altogether. Countries studied by the authors were choosing to use health information systems as one of many strategies to alleviate concerns, these countries as stated by the authors, established policies to drive the adoption of health information systems, or even mandate them, thereby placing physician offices in a position where they were implementing systems even if they were not ready for such change.

In their discussion, [8] revealed that their literature review was a comprehensive systematic search of several sources to understand factors which affect implementations of health information systems in general practice. They provided a chart as shown Figure 2 to illustrate several factors which affect the goal of implementation success. This chart shows the "fit factor" or "socio-technical factor" directly adjacent to the project goal, as the review found it can directly influence implementation success. The authors also mentioned that implementers also had concerns over privacy, patient safety, provider or patient relations, staff anxiety, time needed to implement, quality of care, financial, efficiency, and liability. From their research the authors highlighted that these risks can be managed through sound project management, strong leadership, and implementation of standardized terminologies and staff training as stated in articles they researched. This [8] illustrated in Figure 2, by showing four 
insulating factors inserted between risk factors and the project goal.

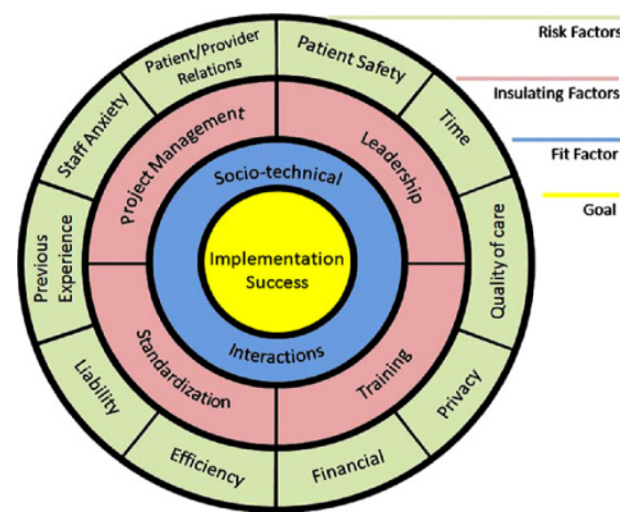

Figure 2. Insulating and Risk Factors

\subsection{The Impact of Technology}

The research of [7] believed that implementing an information technology system can impact more than just quality of care and patient outcomes. The authors therefore proposed a four (4) years, observational research project to examine changes in organizational culture Quality Improvement (QI) maturity, and quality of care following adoption of a single electronic health record (EHR) system within an integrated healthcare network. The authors' main results were to measure the Culture and Quality Questionnaire (CQQ), and assess the perceived culture of an organization and the degree of CQI maturity in seven quality management areas.

According to [7], the authors distributed Baseline surveys before the conversion to the EHR system. They then collected primary data over a period, 12 months post "go live" and subsequently, 24 and 36 months after the first hospital "go live". The authors used routinely collected patient satisfaction measures and standard quality indicators to abstract secondary data. [7] findings proved contrary to their expectation, the Baseline and 12 month followup data suggested that employees perceived the organizational culture as becoming more, rather than less, hierarchical. Also the authors had hypothesized that quality indicators would show improvement due to enhanced information flow and ease of information retrieval, this was not supported by 1-year results. According to [7], years two and three follow-up data may have provided different results. From its research, the authors revealed that IT tools, such as computerized clinical decision support systems and computerized physician order entry, can improve physician performance and patient outcomes. The authors went on to point out that, from their research it became increasingly clear that successful implementation and utilization of IT systems (and their resultant effects on care) depends on a variety of factors. Some of the factors the authors mentioned included technical, individual, and organizational variables. What [7] believed is that the ultimate shape and "success" of IT depends upon and emerges from a complex, multidimensional interaction between IT and the individual and organizational users. It was the belief of the authors that in order to more fully understand the outcome of IT implementation efforts, one should consider the relationships between systems, individual and organizational characteristics and how they affect each other. The authors reported initial (i.e. first 12 month follow-up) results from their 4 years project, evaluating changes in organizational culture and quality, during and subsequent to conversion to an electronic health record (EHR). The authors also provided some preliminary information on the relationship between one important organizational characteristic, organizational culture, and the impact of a new IT initiative, the implementation of a system wide EHR, on quality of care. Several limitations to their research [7] pointed to were:

1. The authors were only able to survey managerial level staff and above due to finite resources. They believed that employees at other levels may have answered their surveys very differently.

2. Their research was done as an observational study. They found that there were potential confounding factors within the organization and the larger healthcare arena that they were unable to control (for e.g. mandated changes in employee benefit packages, provider salary structure) and that may have influenced their results.

3. Finally, since the authors' focused on group level rather than individual-level attributes and wanted to obtain input from a large number of people in the most efficient way possible, they used only quantitative measures to assess culture and degree of CQI maturity.

\section{Method}

The study employed a mixed method design and used two instruments for data collection. The instruments used were 1) the random sampling survey of users impacted by the Health Clinic Online Appointment Scheduling system and the Pharmacy Pharm Partner system and 2) interviews of key personnel involved in the implementation of these systems. Both quantitative and qualitative approaches were employed. The two data type instruments that were used were the User's Survey - Online and Paper-based and Interviews of key personnel, the Health Clinic Administrator and the Pharmacy Manager. The general interview guide was structured that included implementation background, post implementation process, including goals, training, health information system support and changes in the working environment. The survey conducted was a Simple Random Sample (modeled from the Questionnaire for User Interface Satisfaction). Three Survey forms were used, one each for the Health Clinic staff, Pharmacy staff and the wider University population impacted by the Health Clinic Online Appointment Scheduling system

The university main campus is located in the Greater Kingston Metropolitan Region in Papine, in the parish of St. Andrew. The sites that were studied were the University of Technology Jamaica Health Clinic and the University of Technology Jamaica Pharmacy, both located at the University of Technology, Jamaica. The population size of approximately 13500 (Staff \& students) had General Users Online Appointment Scheduling system $(n=$ 153), health clinic staff $(n=9)$ and Pharmacy staff $(n=8)$. To have a reasonable sample from which to make suitable 
generalization, 1870 students and staff were asked to participate in this survey. This gave a required sample size of approximately 374 respondents, with a margin of error of $5 \%$, confidence level of $95 \%$ and an estimated response rate of $20 \%$. The research survey was inclusive of University of Technology Jamaica Health Clinic staff, Pharmacy staff, Office staff, Lecturers, wider University staff, Part time and Full time students who were 18 years and older. The research excluded non University staff and students below the age of 18 years old.

\section{Data Analysis}

Survey data collected primarily through self-administered questionnaires \& online questionnaires using Google Forms. The Statistical Package for the Social Science (SPSS) software version 24, distributive statistics frequency test and Kruskal Wallis Nonparametric Test were used to analyze the data. Interviews answers were organized through the data management tool NVivo for windows version 11.4.1.1064 software.

\section{Results and findings}

Structured interviews were conducted with both the University of Technology Jamaica Health Clinic and Pharmacy to answer two of the three research questions, similar to the one carried out by [1] in their research.

Table 1: Analysis of the health clinic interview

Research Question 1: How did the quality of working life for Health Clinic staff change after the implementation of the Online Appointment Scheduling System within the University of Technology health care environment?

\begin{tabular}{|c|c|c|c|}
\hline \multicolumn{4}{|c|}{ Health Clinic } \\
\hline $\begin{array}{l}\text { Question } \\
\text { Structure }\end{array}$ & $\begin{array}{l}\text { Findings \& } \\
\text { Results }\end{array}$ & $\begin{array}{l}\text { Question } \\
\text { Structure }\end{array}$ & $\begin{array}{l}\text { Findings } \\
\text { \& Results }\end{array}$ \\
\hline $\begin{array}{l}\text { Post } \\
\text { Implementation } \\
\text { process: }\end{array}$ & $\begin{array}{l}\text { Noticeable } \\
\text { increase in the } \\
\text { dependency of } \\
\text { computers. } \\
\text { Staff and } \\
\text { patients were } \\
\text { complimentary. } \\
\text { General } \\
\text { attitude of staff } \\
\text { was that } \\
\text { quality of work } \\
\text { life improved. }\end{array}$ & $\begin{array}{l}\text { Changes in } \\
\text { working } \\
\text { environment: }\end{array}$ & $\begin{array}{l}\text { Improved } \\
\text { flow in } \\
\text { the work } \\
\text { process. } \\
\text { Less } \\
\text { crowded } \\
\text { waiting } \\
\text { area. } \\
\text { Staff } \\
\text { excited } \\
\text { working } \\
\text { with the } \\
\text { system }\end{array}$ \\
\hline Issues. & $\begin{array}{l}\text { Inability to } \\
\text { logon network, } \\
\text { inaccessible } \\
\text { appointment } \\
\text { slots, increased } \\
\text { input time. }\end{array}$ & & \\
\hline
\end{tabular}

Table 2: Analysis of the pharmacy interview
Research Question 2: How did the quality of working life for Pharmacy staff change after the implementation of the Pharm Partner System within the University of Technology Pharmacy environment?

\begin{tabular}{|c|c|c|c|}
\hline \multicolumn{4}{|c|}{ Pharmacy } \\
\hline $\begin{array}{l}\text { Question } \\
\text { Structure }\end{array}$ & $\begin{array}{l}\text { Findings \& } \\
\text { Results }\end{array}$ & $\begin{array}{l}\text { Question } \\
\text { Structure }\end{array}$ & $\begin{array}{l}\text { Findings \& } \\
\text { Results }\end{array}$ \\
\hline $\begin{array}{l}\text { Post } \\
\text { Implement } \\
\text { ation } \\
\text { process: }\end{array}$ & $\begin{array}{l}\text { Noticeable } \\
\text { increase in the } \\
\text { dependency of } \\
\text { computers. } \\
\text { Records are now } \\
\text { kept in database. } \\
\text { Information is } \\
\text { retrieved by } \\
\text { patients' ID. } \\
\text { Search time and } \\
\text { Processing time } \\
\text { reduced. General } \\
\text { attitude of staff } \\
\text { was that quality } \\
\text { of work life } \\
\text { improved. }\end{array}$ & $\begin{array}{l}\text { Changes in } \\
\text { working } \\
\text { environment: }\end{array}$ & $\begin{array}{l}\text { Increased } \\
\text { efficiency, } \\
\text { improved } \\
\text { inventory } \\
\text { managemen } \\
\text { t and } \\
\text { reduced } \\
\text { search time. } \\
\text { Positive } \\
\text { attitude by } \\
\text { staff. }\end{array}$ \\
\hline Issues. & $\begin{array}{l}\text { Staff reported } \\
\text { physical problems } \\
\text { due to prolong } \\
\text { computer usage }\end{array}$ & & \\
\hline
\end{tabular}

Table 3: Analysis health clinic staff survey question 1

Research Question 1: How did the quality of working life for Health Clinic staff change after the implementation of the Online Appointment Scheduling System within the University of Technology health care environment?

\section{Health Clinic Staff}

\begin{tabular}{|l|l|}
$\begin{array}{l}\text { Survey } \\
\text { Question }\end{array}$ & $\begin{array}{l}\text { Are you able to efficiently complete } \\
\text { your work using this system? }\end{array}$ \\
\hline $\begin{array}{l}\text { Analyze } \\
\text { Descriptive } \\
\text { Statistics } \\
\text { Frequency } \\
\text { Test }\end{array}$ & $\begin{array}{l}9 \text { staff members responded to this question } \\
77.78 \% \text { said 'Most of the Time' } \\
11.11 \% \text { said 'Sometimes' }\end{array}$ \\
\hline $\begin{array}{l}\text { Surveyed } \\
\text { Category }\end{array}$ & Online Appointment System $(P<0.05)$ \\
\hline P-value & $P$ value $=0.570$ \\
\hline Hypothesis & $\begin{array}{l}\text { H0 'The answers for each roles/positions } \\
\text { were equal, there was statistically no }\end{array}$ \\
\hline significant difference in mean rank \\
answers for the different roles/positions'.
\end{tabular}

Table 4: Analysis health clinic staff survey question 2 
Research Question 1: How did the quality of working life for Health Clinic staff change after the implementation of the Online Appointment Scheduling System within the University of Technology health care environment?

\section{Health Clinic Staff}

\begin{tabular}{|l|l|}
\hline $\begin{array}{l}\text { Survey } \\
\text { Question }\end{array}$ & $\begin{array}{l}\text { What is your overall experience using } \\
\text { the Online Appointment System to } \\
\text { Fulfilling a patient appointment? }\end{array}$
\end{tabular}

\begin{tabular}{l|l} 
Analyze & 9 staff members responded to this question \\
Descriptive & $66.67 \%$ said 'Very Good' \\
Statistics & $11.11 \%$ said 'Excellent' \\
Frequency & $11.11 \%$ said 'Good' \\
Test & $11.11 \%$ said 'Satisfactory'
\end{tabular}

\begin{tabular}{|l|l|}
$\begin{array}{l}\text { Surveyed } \\
\text { Category }\end{array}$ & Online Appointment System $(P<0.05)$ \\
\hline
\end{tabular}

P-value $\quad P$ value $=0.254$

Hypothesis H0 'The answers for each roles/positions were equal, there was statistically no significant difference in mean rank answers for the different roles/positions'.

Decision Fail to Reject null hypothesis

Table 5: Analysis pharmacy staff survey question 1

Research Question 2: How did the quality of working life for Pharmacy staff change after the implementation of the Pharm Partner System within the University of Technology Pharmacy environment?

\section{Pharmacy Staff}

\section{Survey \\ Question}

Analyze

Descriptive

Statistics

Frequency

Test

Surveyed

Category

P-value

Hypothesis

Decision
Are you able to efficiently complete your work using this system?

8 staff members responded to this question $75.00 \%$ said 'Most of the Time $25.00 \%$ said 'Sometimes'

Online Appointment System $(P<0.05)$

$P$ value $=0.564$

$\mathrm{H} 0$ 'The answers for each roles/positions were equal, there was statistically no significant difference in mean rank answers for the different roles/positions'.

Fail to Reject null hypothesis
Research Question 2: How did the quality of working life for Pharmacy staff change after the implementation of the Pharm Partner System within the University of Technology Pharmacy environment?

\section{Pharmacy Staff}

\begin{tabular}{|c|c|}
\hline $\begin{array}{l}\text { Survey } \\
\text { Question }\end{array}$ & $\begin{array}{l}\text { What is your overall experience using the } \\
\text { Pharmacy Prescription System to fill a patient } \\
\text { prescription? }\end{array}$ \\
\hline $\begin{array}{l}\text { Analyze } \\
\text { Descriptive } \\
\text { Statistics } \\
\text { Frequency } \\
\text { Test }\end{array}$ & $\begin{array}{l}8 \text { staff members responded to this question } \\
37.50 \% \text { said 'Satisfactory' } \\
25.00 \% \text { said 'Very Good' } \\
25.00 \% \% \text { said 'Good' } \\
12.50 \% \text { said 'Excellent' }\end{array}$ \\
\hline $\begin{array}{l}\text { Surveyed } \\
\text { Category }\end{array}$ & Online Appointment System $(P<0.05)$ \\
\hline P-value & $P$ value $=0.365$ \\
\hline Hypothesis & $\begin{array}{l}\text { H0 'The answers for each roles/positions were equal, } \\
\text { there was statistically no significant difference in } \\
\text { mean rank answers for the different roles/positions'. }\end{array}$ \\
\hline
\end{tabular}

Decision Fail to Reject null hypothesis

Table 7: Analysis general users survey question 1

Research Question 3: How did the Online Appointment Scheduling system provided improvements in appointment scheduling to the general users who were impacted by the system implementation?

\section{General Users}

\begin{tabular}{|c|c|}
\hline $\begin{array}{l}\text { Survey } \\
\text { Question }\end{array}$ & $\begin{array}{l}\text { How long do you have to wait after arriving } \\
\text { at the prescribed time given for your } \\
\text { scheduled appointment? }\end{array}$ \\
\hline $\begin{array}{l}\text { Analyze } \\
\text { Descriptive } \\
\text { Statistics } \\
\text { Frequency } \\
\text { Test }\end{array}$ & $\begin{array}{l}149 \text { out } \mathrm{f} 153 \text { persons responded to this question } \\
36.24 \% \text { said 'At least } 15 \text { minutes waiting time' } \\
27.52 \% \text { said 'More than an hour' } \\
17.45 \% \text { said 'I see the doctor according to my } \\
\text { appointment time } \\
8.73 \% \text { said 'Sometimes Half day' } \\
5.37 \% \text { said 'I see the doctor immediately' } \\
4.69 \% \text { said 'Sometime I do not get to see a } \\
\text { doctor' }\end{array}$ \\
\hline $\begin{array}{l}\text { Surveyed } \\
\text { Category }\end{array}$ & Online Appointment System $(P<0.05)$ \\
\hline P-value & $P$ value $=0.259$ \\
\hline Hypothesis & $\begin{array}{l}\text { H0 'The answers for each roles/positions were } \\
\text { equal, there was statistically no significant } \\
\text { difference in mean rank answers for the } \\
\text { different roles/positions'. }\end{array}$ \\
\hline Decision & Fail to Reject null hypothesis \\
\hline
\end{tabular}


Research Question 3: How did the Online Appointment Scheduling system provided improvements in appointment scheduling to the general users who were impacted by the system implementation?

\section{General Users}

\begin{tabular}{|l|l|}
$\begin{array}{l}\text { Survey } \\
\text { Question }\end{array}$ & $\begin{array}{l}\text { What is your overall experience using the } \\
\text { Online Appointment System to make an } \\
\text { appointment? }\end{array}$ \\
\hline $\begin{array}{l}\text { Analyze } \\
\text { Descriptive } \\
\text { Statistics } \\
\text { Frequency } \\
\text { Test }\end{array}$ & $\begin{array}{l}\text { Out of the } 153 \text { persons surveyed } \\
147 \text { persons responded to this question } \\
41.50 \% \text { said 'Very Good' } \\
27.89 \% \text { said 'Good' } \\
17.69 \% \text { said 'Satisfactory' } \\
9.52 \% \text { said 'Excellent' } \\
3.40 \% \text { said 'Poor' }\end{array}$ \\
\hline $\begin{array}{l}\text { Surveyed } \\
\text { Category }\end{array}$ & $\begin{array}{l}\text { Online Appointment System }(P<0.05) \\
\text { P-value }\end{array}$ \\
\hline Hypothesis & $\begin{array}{l}\text { H0 'The answers for each roles/positions were } \\
\text { equal, there was statistically no significant } \\
\text { difference in mean rank answers for the } \\
\text { different roles/positions'. }\end{array}$ \\
\hline Decision & Fail to Reject null hypothesis \\
\hline
\end{tabular}

\section{Discussions Online Appointment Scheduling/Pharm Partner Systems}

The results revealed that the processing time on arrival at the Health Clinic/Pharmacy were more efficient and less time consuming since the implementation of the new system. Pharmacy/Health Clinic staffs depended on the technologies to better function in their jobs. Results showed that both systems automated certain manual processes/reporting procedures that were resource manual intensive. These results reflected [1], that showed that the work of clinical and office staff changed significantly (reduction in time spent distributing charts, transcription and other clerical tasks, etc.) The general users believed that their waiting time overall was shorter and over $78 \%$ believed that their overall experience using the systems were from good, very good to excellent. This was reported performance of $P$-values was 0.238 . Although statistically no significant difference in answer given between the different roles/positions, this was similar [1] who reported performance $P$ value $=0.800$ with statistically no significant difference. This was in contrast to [7] research which $P$ values were mostly below 0.05 , indicating statistical significant differences.

The quality of working life indicators showed improvement since the technologies were implemented in both facilities. This was observed in reduced waiting time, automation of processes, ease of access to services and increase in employee's satisfaction. This reflected [6] and [1] work which showed improvement of quality of working life for job satisfaction.

\section{Conclusion}

The Technologies have improved the quality of working life of the users they impacted. The systems users have seen a vast improvement in the way they carried out their functions since the system implementation, therefore an improvement in their quality of working life. This was a perceptual study; quality of working life was greatly influenced by the personal characteristics of those who determine it. Determining the quality of working life always involved the interplay between and among the worker, the users, job content, job context and the technology. This was in keeping with the literatures of [8], [1] and [7] who believed that technology will impact the quality of life of users but also organization and human factors will impact also. It was realized that technologies improved the quality of working life of the users.

This research just like [6] was not a refutation of previous studies. It was suggested that as technology use broadens, one should not assume an automatic diffusion of improved quality of working life to users.

\section{Conflict of Interest}

The authors declare no conflict of interest.

\section{References}

[1] P. Carayon, P. Smith, A. Hundt, V. Kuruchittham, \& Q. Li, Implementation of an electronic health records system in a small clinic: the viewpoint of clinic staff. Behaviour \& Information Technology, 28(1), 5-20, 2009.

[2] M. Yusof., A. Papazafeiropoulou, R. Paul \& L. Stergioulas, Investigating evaluation frameworks for health information systems. International Journal of Medical Informatics, 77(6), 377-385, 2008.

[3] D. Bell, S. Cretin, R. Marken, \&A. Landman, A conceptual framework for evaluating outpatient electronic prescribing systems based on their functional capabilities. Journal of the American Medical Informatics Association, 11(1), 60-70, 2004.

[4] J. Ash \& D. Bates, Factors and forces affecting EHR system adoption: report of a 2004 ACMI discussion. Journal of the American Medical Informatics Association, 12(1), 8-12, 2005.

[5] J. Anderson, Social, ethical and legal barriers to e-health. International Journal of Medical Informatics, 76(5), 480-483, 2007.

[6] J. Linder., J. Ma, D. Bates, B. Middleton \& R. Stafford, Electronic health record use and the quality of ambulatory care in the United States. Archives of internal medicine, 167(13), 1400-1405, 2007.

[7] C. Nowinski, S .Becker, K. Reynolds, J. Beaumont, C. Caprini., E. Hahn. $\&$ B. Arnold, The impact of converting to an electronic health record on organizational culture and quality improvement. International Journal of Medical Informatics, 76, S174-S183, 2007.

[8] D. Ludwick \& J. Doucette, Adopting electronic medical records in primary care: lessons learned from health information systems implementation experience in seven countries. International Journal of Medical Informatics, 78(1), 22-31, 2009.

[9] V. Rama Devi \& S. Charan, Conceptual Model for Effective Change Management, 2013. 